\title{
A regression model for the spatial distribution of red-crown crane in Yancheng Biosphere Reserve, China ${ }^{1}$
}

\author{
Wenjun Li, Zijian Wang *, Zhijun Ma, Hongxiao Tang \\ State Key Laboratory of Environmental Aquatic Chemistry, Research Center for Eco-Environmental Sciences, \\ Chinese Academy of Sciences, P.O. Box 2871, Beijing 100085, People's Republic of China
}

Accepted 26 March 1997

\begin{abstract}
A logistic regression of principal components, in combination with spatial autocorrelation analysis, was developed to simulate and predict the distribution of species. The model was tested by the matching coefficient $\left(m_{1}+m_{2}\right) / n$, which was obtained by comparing the observed and the predicted presence/absence data of species. The results from the case study for red-crown crane (Grus japonensis) in Yancheng Biosphere Reserve, Eastern China, showed that the matching coefficient of the model was as high as $91.13 \%$. (C) 1997 Elsevier Science B.V.
\end{abstract}

Keywords: Principal components analysis; Autocorrelation; Logistic regression; Species distribution; Geographical information system

\section{Introduction}

Although the general habitat associations of many species are already known through observation in the field, modeling analysis is an important methodology for ecologists to further study in wildlife distribution (Wiens et al., 1987). In conservation biology the two primary aims of the

* Corresponding author. Tel.: + 861062923541 ; fax: + 86 10 62923563; e-mail: wangzj@mail.rcees.ac.cn

${ }^{1}$ This work is supported by Chinese Natural Science Foundation. model studies are associated with prediction; for example, the prediction of species distributions in poorly documented areas and prediction of the areas into which a re-introduced species may be expected to spread (Fielding and Haworth, 1995). Besides these, models may also be used to predict how a species will respond to habitat modifications; for example, to climatic change (Gates et al., 1994) or land-use change (Marquiss et al., 1985; Haworth and Thompson, 1990; Watson, 1992).

In modeling analysis, the high correlation between independent variables and the spatial autocorrelation in each variable are two of the main 
aspects affecting the precision of the regression model. To eliminate high correlation between independent variables, Osborne and Tigar (1992) proposed using principal components analysis in logistic regression for modeling wildlife distributions. However, in their study the spatial autocorrelation in each variable was ignored. A different approach to modeling wildlife distributions was developed by Augustin et al. (1996), in which the spatial autocorrelation was included in the model, but the correlation between independent variables was not discussed.

In this study, a logistic regression of principal components in combination with spatial autocorrelation analysis is developed to simulate and predict the distribution of red-crown crane (Grus japonensis), a worldwide endangered bird species living in Yancheng Biosphere Reserve, Eastern China, during the winter.

\section{Methods}

The geographical information system software ARC/INFO is applied to analyze the spatial data. The hardware used for the study is a DEC workstation. The grid format of variable data is used, and the cell size is $60 \times 60 \mathrm{~m}$.

\subsection{Variables sampling}

Sampling is the first step in any statistic analysis, and a key step that is usually overlooked. All statistical analyses are based on the observed value of samples. The conclusions of statistical analyses are useful only when the obtained samples can represent the entire background of the population.

The random-systematic sampling method for variables is used in this study. The random sampling (Tao, 1994), in which each cell has the same chance to be sampled, is applied first. Then the systematic sampling method (Haining, 1980; Pereira and Itami, 1991), which can reduce the spatial autocorrelation existing in each variable, is followed.

Spatial autocorrelation analysis is used to identify whether the variable value of a given site is correlated with the value of its neighboring sites (Cliff and Ord, 1981). If the variable value of a given site increases with the value of its neighboring sites, a positive spatial correlation exists in the variable; if it decreases, a negative spatial correlation exists; if it is irrelevant, no spatial autocorrelation exists (Turner et al., 1990).

Moran's I coefficient (Cliff and Ord, 1981; Upton and Fingleton, 1985) is applied to assess spatial autocorrelation. The formula is as follows:

$I=\frac{n \sum_{i=1}^{n} \sum_{j=1}^{n} W_{i j}\left(X_{i}-\bar{X}\right)\left(X_{j}-\bar{X}\right)}{\left(\sum_{i=1}^{n} \sum_{j=1}^{n} W_{i j}\right) \sum_{i=1}^{n}\left(X_{i}-\bar{X}\right)^{2}}$

where $i$ and $j$ are any two adjacent cells; $X_{i}$ and $X_{j}$ are the values of variable $X$ in the cell $i$ and cell $j$, respectively; $\bar{X}$ is the mean value of $X ; W_{i j}$ is the similarity of $i$ and $j$ 's location, $W_{i j}=1$ if cells $i$ and $j$ are directly adjacent (4-adjacent) and 0 otherwise; and $n$ is the total number of cells in the study area. The value of Moran's $I$ is placed between -1 and +1 . It represents no spatial autocorrelation when $I=0$, positive autocorrelation when $I$ is positive, and negative autocorrelation when $I$ is negative.

One method of reducing the spatial autocorrelation is to group small areas together into larger units that might be more independent of each other (Hall, 1988). The autocorrelation coefficient decreases with an enlarging of the sampling lag. During the systematic sampling, the cells are sampled over every lag (counted in the number of the cells) for each row and column. The used lag should enable the autocorrelation coefficient in each variable to be nearly zero.

\subsection{Principal components regression}

The method of principal components analysis is used to obtain required principal components. Through the principal components analysis, the original independent variables are linearly composed into several orthogonal comprehensive variables. The formula of principal components is as follows: 
$P C_{i}=V_{i 1} X_{1 i}+V_{i 2} X_{2 i}+\cdots+V_{i j} X_{j i}+\cdots+V_{i m} X_{m i}$

where $P C_{i}$ is a principal component, $V_{i j}$ is the coefficient corresponding to the independent variable $X_{j i}$.

The coefficients' matrix $\mathbf{V}$ is composed of the eigenvectors from the covariance matrix of independent variables. The eigenvalues of the covariance matrix present the principal components' ability comprehensively reflecting the variables $X_{1}, X_{2}, \ldots, X_{m}$. The larger the eigenvalue is, the higher the ability of reflecting the original variables is (Zhang, 1988).

A logistic regression model is developed for the obtained principal components to simulate the distribution of species as follows:

$\log \left(\frac{P_{i}}{1-P_{i}}\right)=a_{0}+a_{1} \mathrm{PC}_{1 i}+a_{2} \mathrm{PC}_{2 i}+\cdots+a_{n} \mathrm{PC}_{n i}$

where $P_{i}$ is the present probability of wildlife in the cell $i$, with values between 0 and $1, a_{i}$ is the regression coefficient.

\subsection{Model test}

The model is tested through calculating the matching coefficient of the observed and predicted presence/absence data (Buckland and Elston, 1993; Augustin et al., 1996). As shown in Table 1, $m_{1}$ and $m_{2}$ represent the numbers of correctly classified cells, while $n_{1}$ and $n_{2}$ represent the numbers of misclassified cells. The matching coefficient $\left(m_{1}+m_{2}\right) / n$ is used to assess the proportion of correctly classified cells.

Table 1

Matching counts: a method to assess the matching of predicted cells and observed cells

\begin{tabular}{llll}
\hline Observed distribution & \multicolumn{2}{c}{ Predicted distribution } & \\
\cline { 2 - 3 } & Present & Absent & Total \\
\hline Present & $m_{1}$ & $n_{1}$ & \\
Absent & $n_{2}$ & $m_{2}$ & \\
Total & & & $n$ \\
\hline
\end{tabular}

\section{The case study}

Yancheng Biosphere Reserve (YBR) was established in 1983 with the main aim of protecting an endangered bird species, the red-crown crane (Grus japonensis). It was approved as an International Biosphere Reserve in UNESCO's Man and Biosphere Program in 1992. The reserve is located in the east coast of China and extends $582 \mathrm{~km}$ along the coast of the Yellow Sea. It lies within Jiangsu Province and covers five counties (Management Office of YBR, 1995).

YBR is a typical coastal wetland with a total area of $2800 \mathrm{~km}^{2}$. The vegetation in the YBR is mainly grass growing on the salt lick. The extensive reedbeds of Phragmites australis predominate in many areas. There are also extensive grass and sedge marshes including dominant species such as Scirpus planiculmis, S. triqueter, Carex scabrifolia, Cortaderia celloana and Panicum psilopodium, and saline marshes such as goosefoot Suaeda salsa (Yan, 1991). YBR is the largest wintering habitat for red crown cranes. The total number of redcrowned crane in YBR increased from 361 in 1983, when the reserve was founded, to 876 in 1993 (Liu, 1990). In the recent years, the number of the birds has been about 700 , this represents more than half of the total number of individuals in the world.

\subsection{Data}

The habitat survey in 1995 as well as past studies (Liu, 1990; Yan, 1991) showed that the cranes prefer to live in the upper tidal mudflat, in which the salinity is lower, reed and high grass species are predominant and the food sources abound with Claratula, Assiminea latericea, little fish, little crabs, grass seeds, and grass roots, etc. The types of beach in YBR include depositional and eroded mudflat. The red-crown cranes prefer to live in the depositional mudflat where the beach is wider and thus receives less influence from human beings. Therefore, the relationship between red-crown crane and its environment is primarily shaped according to appropriate food sources, salinity, land cover, beach type, and road networks. The last variable is selected according 
Table 2

Independent variables and their definitions

\begin{tabular}{|c|c|}
\hline Variable & Definition \\
\hline $\begin{array}{l}\text { Food productiv- } \\
\text { ity }\end{array}$ & $\begin{array}{l}\text { Three categories: } 0-185.6 \mathrm{~g} / \mathrm{m}^{2}, 185.6- \\
372.8 \mathrm{~g} / \mathrm{m}^{2},>372.8 \mathrm{~g} / \mathrm{m}^{2}\end{array}$ \\
\hline Road network & $\begin{array}{l}\text { Distance to road: } 0-600 \mathrm{~m}, 600-1200 \\
\mathrm{~m},>1200 \mathrm{~m}\end{array}$ \\
\hline Land cover & $\begin{array}{l}\text { Nine categories: Sea water, mudflat, } \\
\text { Spartinaang lica, Suaeda salsa, aquacul- } \\
\text { ture land, salt pan, grassland, reed, } \\
\text { farmland }\end{array}$ \\
\hline Salinity & $\begin{array}{l}\text { Three categories: } 0-11.77 \mathrm{mg} / 1,11.77- \\
23.54 \mathrm{mg} / \mathrm{l},>23.54 \mathrm{mg} / \mathrm{l}\end{array}$ \\
\hline Seashore type & Two categories: eroded, depositional \\
\hline
\end{tabular}

the experience of the manager working in the YBR. The variables and their definitions are listed in Table 2. For the continuous variables, food productivity and salinity, the equal division method (Pereira and Itami, 1991; Herr and Queen, 1993) is used to transform them into ordinary variables.

The map of land cover is generated by using supervised classifications of remote sensing data, Landsat TM, 1988. Comparing these data with a current field survey, it is observed that there have been no significant changes of land cover types in the YBR during the past decade. Therefore it is thought that the temporal variation will not affect the research results.

The seaboard types are also obtained from remote sensing data as well as coastal study (Cheng et al., 1992), which is used to identify the deposit and erosive types in the seaboard.

The food productivity is obtained from the original data of the field work in November 1995. The sample sites are digitized and the point coverage is formed. It is then converted into grid format.

The variable salinity is obtained in the same way as the productivity of food.

The road network is digitized from a topographic map at a scale of 1:200000, and then converted into grid format.

The dependent variable, distribution data of cranes, is obtained from field survey data in
1991-1994, as shown in Fig. 1. It is transformed into presence/absence data, the cells with cranes present (active sites in Fig. 1) are assigned a value $=1$, otherwise (inactive sites in Fig. 1) a value $=0$ is assigned.

\subsection{Principal components analysis}

Through principal components analysis, five principal factors are obtained (Table 3). The first component $P C_{1}$ is related to land cover; $P C_{2}$ to road networks; $P C_{3}$ to road and salinity; $P C_{4}$ to food productivity; and $P C_{5}$ to seashore type. The eigenvalue of $P C_{1}$ is the biggest, thus its ability to comprehensively reflect the variables is highest; The eigenvalue of $P C_{5}$ is smallest, so its ability to comprehensively reflect the variables is lowest.

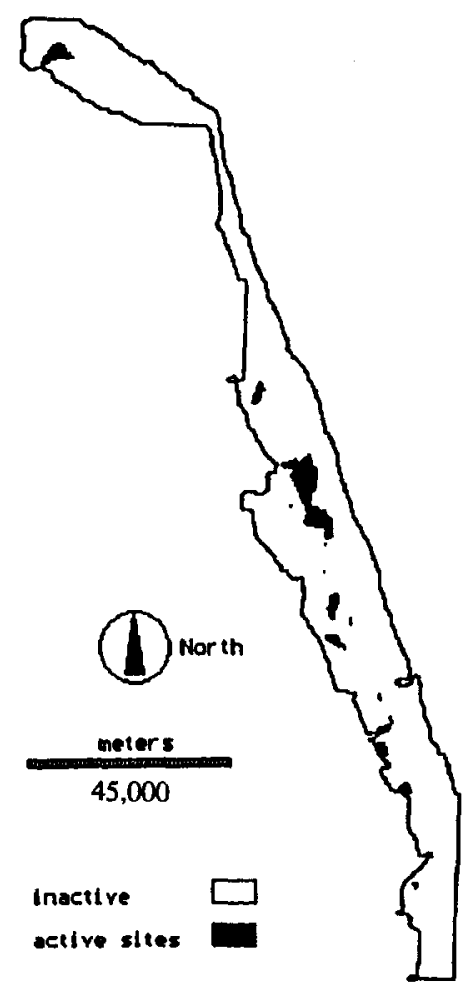

Fig. 1. Distribution map of cranes from field survey in the YBR (The Yellow Sea is located outside the right boundary and inland outside the left boundary). 
Table 3

Correlation between the principal components and the original variables (with their eigen values)

\begin{tabular}{lrrrrr}
\hline Original variable & \multicolumn{2}{l}{ Principal component } & & & \\
\cline { 2 - 5 } & \multicolumn{1}{c}{$P C_{1}$} & $P C_{2}$ & $P C_{3}$ & $P C_{4}$ & $P C_{5}$ \\
\hline Food productivity & 0.066 & 0.356 & -0.457 & 0.710 & -0.373 \\
Road network & -0.102 & 0.780 & 0.599 & -0.055 & -0.141 \\
Land cover & 0.989 & 0.018 & 0.142 & -0.012 & -0.010 \\
Salinity & -0.066 & -0.366 & 0.580 & 0.692 & 0.216 \\
Seashore type & 0.039 & 0.361 & -0.244 & 0.120 & 0.891 \\
Eigenvalues & 0.799 & 0.083 & 0.063 & 0.052 & 0.013 \\
\hline
\end{tabular}

\subsection{Sampling schedule}

After a calculation of Moran's I using a series of ascending sampling lags, a systematic sampling method is generated. Since the shape of the reserve is a strip, different sampling lags are used in row and column directions, respectively, to keep the sampling cells as typical as possible while the spatial autocorrelation in each variable is enabled to be nearly zero. For the final sampling schedule, each 5th cell in the database is selected in row direction and each 50th cell is selected in columns.

The autocorrelation coefficients of variables (before and after sampling) are given in Table 4. The values show that all variable samples have high positive autocorrelations before sampling, whilst they become spatially independent after sampling.

\subsection{Results}

The coefficients are yielded through logistic regression of principal components, as shown in Table 5. The present probability of red-crown cranes in each cell is calculated according to Eq. (3). The results are shown in Fig. 2. The legend 'unsuitable habitat' is assigned to those sites where the probability is $0-0.3$, 'subsuitable' is assigned to sites where the probability is $0.3-0.5$, and 'suitable' is assigned to 0.5-1.0.

Fig. 2 is transformed to presence/absence data in order to test the model. The value 1 is assigned to those 'suitable' cells $\left(P_{i}=0.5-1.0\right)$, and otherwise $\left(P_{i}=0-0.5\right)$ the value 0 is assigned. According to the method shown in Table 1, the corresponding counts $m_{1}=8682, \quad n_{1}=28847$, $m_{2}=691361, n_{2}=39303$ are obtained. The proportion of correctly classified cells, the matching coefficient $\left(m_{1}+m_{2}\right) / n$ is obtained to $91.13 \%$. It is thus considered that the model has a satisfactory correctly classified rate.

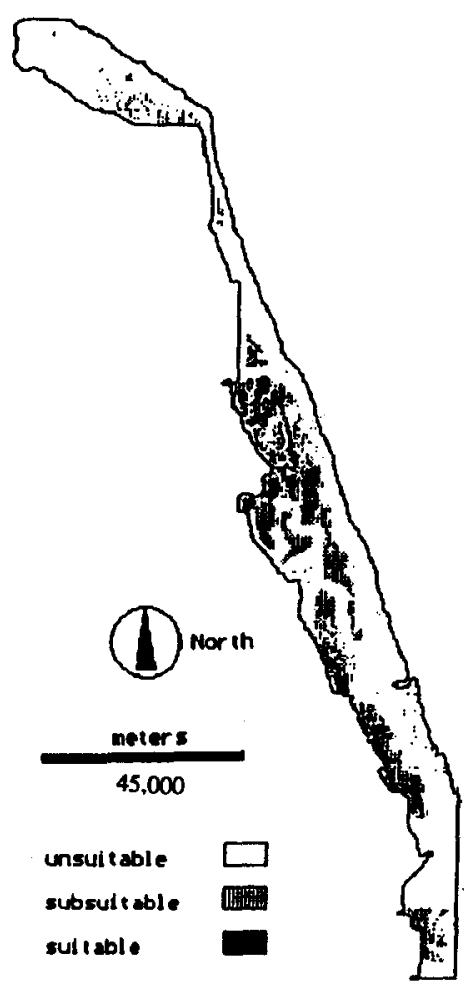

Fig. 2. Distribution map of cranes from model prediction in the YBR (The Yellow Sea is located outside the right boundary and inland outside the left boundary). 
Table 4

Autocorrelation coefficients of principal components (before sampling and after sampling)

\begin{tabular}{llllll}
\hline Principal components & $P C_{1}$ & $P C_{2}$ & $P C_{3}$ & $P C_{4}$ & $P C_{5}$ \\
\hline Before sampling & 0.684 & 0.967 & 0.843 & 0.982 & 0.965 \\
After sampling & 0.000 & 0.000 & 0.000 & 0.000 & 0.000 \\
\hline
\end{tabular}

\section{Discussion}

By combination of principal components analysis and spatial autocorrelation analysis in the logistic regression, a comprehensive new method is proposed in this study. The correlation between independent variables is eliminated by the principal components analysis. The spatial autocorrelation is minimized by the random-systematic sampling method (Haining, 1980; Pereira and Itami, 1991), which is different from the method used by Augustin et al. (1996) who added a term called autocov, for autocorrelation in the general logistic.

The different sampling lags are used in row and column directions, respectively, in consideration of the shape of study area. This systematic sampling method is different from the method applied by Pereira and Itami (1991), who used the same lags both in row and column directions. The advantage of using different sampling lags is that more information in the study area, especially in the narrow direction, can be reserved. As shown in Table 4, a high positive autocorrelation exists in each variable before sampling; while all autocorrelation coefficients are zero after the random-systematic sampling. This result shows that the selected sampling schedule is successful in eliminating the spatial autocorrelation.

The correctly classified rate of the model, i.e. the matching coefficient of the observed and pre- dicted presence/absence data, is $91.13 \%$. This means that the method used is suitable and the results from the model are credible. In addition, the model can be verified through comparison of the model results and the documents from the empirical studies (Liu, 1990; Yan, 1991). As shown in Fig. 2, major suitable habitats are mainly concentrated in the wider seaboard, and located closer inland where the salinity is lower in the reserve. This is consistent with both $\mathrm{Liu}$ (1990) and Yan's 1991 study conclusions.

It was noticed that there is an observed integrated active patch in the north of the reserve (Fig. 1), while in the predicted map there are only some clusters existing (Fig. 2). This may reveal the influence of the salt pan during different evaporation periods. In the north of the reserve, land is mainly taken up by the salt pan (Management Office of YBR, 1995). During the primary period, the salt concentration is almost the same as that of ocean water. The pan has a rich biomass and as a result, some cranes may look for food there. However during the latter period, the salt concentration becomes more and more high due to the process of evaporation. Eventually, organisms can no-longer exist in the pan and it loses its attraction for the cranes. It is therefore considered that the observed habitats located in the salt pan are temporary habitats, which are not affected by the variables selected in the model. For this reason, the habitats in the north are not reflected in the prediction.

Table 5

Coefficients of regression model

\begin{tabular}{llllllll}
\hline & Constant & $P C_{1}$ & $P C_{2}$ & $P C_{3}$ & $P C_{4}$ & $P C_{5}$ & -1.146 \\
\hline Coefficients & -1.258 & 0.317 & 1.426 & -0.619 & -2.301 & -1 \\
\hline
\end{tabular}




\section{Conclusion}

The spatial autocorrelation analysis and the principle components analysis were included in the logistic regression model to simulate and predict the distribution of red-crown crane (Grus japonensis), in Yancheng Biosphere Reserve, Eastern China. The model was tested by the matching coefficient obtained from comparing the observed and predicted presence/absence data of red-crown crane. The resulting regression model was credible and the accuracy of the model was as high as $91.13 \%$.

\section{Acknowledgements}

We would like to thank Mr Hui Wang, the staff working in the Yancheng Biosphere Reserve, and $\mathrm{Mr}$ Xiping Liu, the director of the reserve, for their help in supplying data and information about the reserve. This research was coordinated by Chinese National Committee for MAB Programme. We also would like to thank Ms Xianying Zhao, the general secretary of Chinese National Committee for MAB Program, and $\mathrm{Mr}$ Nianyong Han, the director of the Committee, for their help during the research.

\section{References}

Augustin, N.H., Mugglestone, M.A., Buckland, S.T., 1996. An autologistic model for the spatial distribution of wildlife. $\mathbf{J}$. Appl. Ecol. 33, 339-347.

Buckland, S.T., Elston, D.A., 1993. Empirical models for the spatial distribution of wildlife. J. Appl. Ecol. 30, 478-495.

Cheng, C.J., Cheng, H.Y., Feng, Y., 1992. The Coastal Study in Jiangsu Province (in Chinese). Ocean Press, Beijing, 208 pp.

Cliff, A.D., Ord, J.K., 1981. Spatial processes: Models and Applications. Pion, London.

Fielding, A.H., Haworth, P.F., 1995. Testing the generality of bird-habitat models. Conserv. Biol. 9, 1466-1481.

Gates, S., Gibbons, D.W., Lack, P., Fuller, R.J., 1994. Declining farmland bird species: modeling geographical patterns of abundance in Britain. In: Edwards, P.J., May, R.M.,
Webb, N.R. (Eds.), Thirty-fifth symposium of the British Ecological Society. Scale Ecology and Conservation Biology. Blackwell, Oxford, pp. 153-178.

Haining, R., 1980. Spatial autocorrelation problem. In: Herbert, D.T., Johnston, R.J. (Eds.), Geography and the Urban Environment, vol. 3, pp. 1-43.

Hall, P., 1988. On confidence intervals for spatial parameters estimated from nonreplicated data. Biometrics 44, 271277.

Haworth, P.F., Thompson, D.B.A., 1990. Factors associated with the breeding distribution of upland birds in the South Pennines, England. J. Appl. Ecol. 27, 562-577.

Herr, A.M., Queen, L.P., 1993. Crane habitat evaluation using GIS and remote sensing. Photogram. Eng. Remote Sensing $59,1531-1538$.

Liu, B., 1990. Winter numbers distribution of red crown crane on seabord of Yancheng of Jiangsu Province (In Chinese). ACTA Ecologia SINICA 10, 234-235.

Management Office of YBR, 1995. The Comprehensive Survey Report on Yancheng Bioshphere Reserve (In Chinese). Local Government of Jiangsu Province, Jiangsu.

Marquiss, M., Ratcliffe, D.A., Roxburgh, R., 1985. The numbers, breeding success and diet of Golden Eagles in Southern Scotland in relation to changes in land use. Biol. Conserv. 34, 121-140.

Osborne, P.E., Tigar, B.J., 1992. Interpreting bird atlas data using logistic models: an example from Lesotho, Southern Africa. J. Appl. Ecol. 29, 55-62.

Pereira, J.M.C., Itami, R.M., 1991. GIS-based habitat modeling using logistic multiple regression: acase study of the Mt. Ggraham red squirrel. Photogram. Eng. Remote Sensing 57, 1475-1486.

Tao, S., 1994. Applied Statistics Method (In Chinese). Chinese Environmental Sciences Press, Beijing.

Turner, S.J., O'Neill, R.V., Conley, W., 1990. Parttern and scale: statistic for landscape ecology. In: Turner, Monica G., Gardner, Robert H. (Eds.), Quantitative Methods in Landscape Ecology, pp. 17-51.

Upton, G.J.G., Fingleton, B., 1985. Spatial Data Analysis by Example: Point Pattern and Quantitative Data, vol. 1. Wiley, New York.

Watson, J.. 1992. Golden Eagle Aquila cbrysaetos breeding success and afforestation in Argyll. Bird Study 39, 203206.

Wiens, J.A., Rotenberry, J.T., Van Horne, B., 1987. Habitat occupancy patterns of North American shrubsteppe birds: the effects of spatial scale. OIKOS $48,132-147$.

Yan, F.T., 1991. Wintering distribution and biological study of red crown cranes in Yancheng beach (in Chinese). Chin. J. Zool. 26, 34-36.

Zhang, Q.R., 1988. Practical Regression Analysis (in Chinese). Geology Press, Beijing. 